\title{
Challenges in disaster relief operations: evidence from the 2017 Kermanshah earthquake
}

\author{
Amin Maghsoudi \\ HUMLOG Institute, Hanken School of Economics, Helsinki, Finland and \\ Department of Industrial Engineering, University of Tehran, \\ Tehran, Iran, and \\ Mohammad Moshtari \\ Faculty of Management and Business, Tampere University, Tampere, Finland
}

Challenges of $\mathrm{HL}$ in disaster relief

operations

\begin{abstract}
Purpose - This paper identifies the challenges during a recent disaster relief operation in a developing country where the humanitarian response is dominated by national actors, with international actors having a minor role. Design/methodology/approach - A case study design is used; the main data sources are semi-structured interviews with 43 informants involved in the 2017 Kermanshah earthquake relief operation.

Findings - The findings suggest that humanitarian practitioners deal with multiple challenges during disaster relief operations. One group of challenges relates to humanitarian logistics (HL) like needs assessment, procurement, warehousing, transportation and distribution, all widely discussed in the literature. Another involves the growing use of social media, legitimacy regulations and the engagement of new humanitarian actors (HAs) like social media activists and celebrities. These factors have not been extensively studied in the literature; given their growing influence, they require more scholarly attention.

Practical implications - The findings will help humanitarian practitioners and policymakers better understand the challenges involved in disaster relief operations conducted by multiple actors and thus help them improve their practices, including the creation of proper regulations, policies and logistics strategies.

Originality/value - The study uses primary data on a recent disaster to assess and extend the findings of previous studies regarding $\mathrm{HL}$ challenges. It also elaborates on the critical non-logistical challenges that influence aid delivery in emergency responses, including the growth of social media, regulations and the engagement of new HAs. The results may motivate future empirical and modelling studies to investigate the identified challenges and identify practices to mitigate them.
\end{abstract}

Keywords Humanitarian logistics, Disaster relief operations, Social media, Celebrities, Humanitarian actors, Regulations

Paper type Case study

\section{Introduction}

Traditionally, logistics plays a central role in humanitarian assistance as the connecting point between preparedness and response, procurement and distribution, and headquarters and the field (Thomas, 2008). Humanitarian logistics (HL) has been described as "the process of planning, managing, implementing and controlling the efficient, cost-effective flow and

(C) Amin Maghsoudi and Mohammad Moshtari. Published by Emerald Publishing Limited. This article is published under the Creative Commons Attribution (CC BY 4.0) licence. Anyone may reproduce, distribute, translate and create derivative works of this article (for both commercial and non-commercial purposes), subject to full attribution to the original publication and authors. The full terms of this licence may be seen at http://creativecommons.org/licences/by/4.0/legalcode

The authors gratefully acknowledge Maria Besiou (the associate editor) and two anonymous reviewers for their valuable suggestions and helping to improve the quality of this manuscript. The Academy of Finland (Grant no. 332921) supported this piece of research work. In addition, the authors would like to thank to all respondents whom spent their valuable time with us during the interviews.

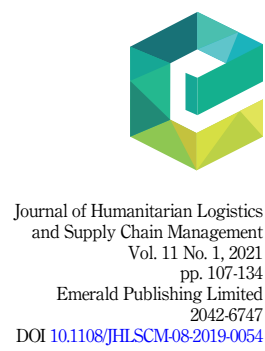

Received 21 August 2019

Revised 12 January 2020

22 January 2020

15 June 2020

17 August 2020

4 October 2020

Accepted 18 November 2020 
JHLSCM 11,1

\section{8}

storage of relief items as well as related information and funds, from the point of origin (suppliers and donors) to the point of consumption for the purpose of meeting the end beneficiary's requirements" (Thomas and Mizushima, 2005, p. 60). HL involves a wide range of activities that includes needs assessments, procurement, resource mobilization, transportation, warehousing and last mile distribution (Gustavsson, 2003). HL activities can account for up to $80 \%$ of the total cost of humanitarian assistance (Van Wassenhove, 2006).

The existing $\mathrm{HL}$ literature discusses a wide range of practical $\mathrm{HL}$ challenges identified during disaster relief operations. These range from specific deficiencies such as a lack of logistical knowledge and trained logisticians, the absence of standards and performance indicators, security problems and inadequate funding and investment in information technology (Fritz Institute, 2004; Maiers et al., 2005; Balcik and Beamon, 2008; Kovács and Spens, 2009; Sandwell, 2011) to general characteristics of the humanitarian environment such as extreme supply and demand uncertainty, the presence of myriad humanitarian actors (HAs), the breakdown of the rule of law and media attention (Thomas and Kopczak, 2005; Van Wassenhove, 2006; Kovács and Tatham, 2009; Sandwell, 2011).

Although previous research has identified many challenges involved in HL, further investigation of and suggestions for understanding challenges and how to mitigate their impact on logistics activities in disaster relief operations can improve humanitarian response and eventually lead to a significant reduction in the level of human suffering. As any disaster relief operation is highly context-specific and dynamic, challenges vary with the type, intensity, location and timing of a given disaster (Kovács and Moshtari, 2019). Over the last decade, humanitarian operations have been affected by new influences like information and communication technology innovations, regulatory changes and the entry of new actors. This study seeks to contribute to this literature by providing additional insights into the both logistical and non-logistical challenges of disaster relief operations through a case study of a recent humanitarian response in a developing county. The findings will help humanitarian practitioners and policymakers better understand the challenges involved in disaster relief operations conducted by multiple actors and thus help them improve their practices, including the creation of proper regulations, policies and logistics strategies. Moreover, the results of the present study can motivate future empirical and modelling studies to investigate the challenges identified and identify practices to mitigate them.

This paper explores a practical approach to identifying the challenges of HL, particularly in cases where established HAs such as government agencies must coordinate with national non-governmental organizations (NGOs), international organizations and new emerging actors like ad hoc groups, celebrities and teams sponsored by religious organizations during disaster relief operations. This paper thus attempts to answer the following research questions: (1) What were the key challenges in disaster relief operations in the 2017 Kermanshah earthquake? and (2) What were the critical challenges in the 2017 Kermanshah earthquake that influenced disaster relief operations but have not been extensively explored in previous studies?

The paper is organized as follows. In section 2 , we provide an overview of the previous $\mathrm{HL}$ literature on all aspects of challenges. In section 3, we describe the case study as a method for this research, while section 4 contains our findings regarding the challenges identified. In section 5 , we provide a discussion of those findings, connecting them back to the HL literature. In section 6 , we present several implications for research and practice, along with study limitations, as a conclusion.

\section{Literature review}

Bölsche et al. (2013) observe that if the right relief items of the right quality and in the right quantities are distributed and received by the right affected population at the right time and in the right place, HL can contribute to alleviating the suffering of vulnerable people. In the 
complex environment of a humanitarian setting, logisticians must first aim to meet beneficiaries' requirements. This task is like the supply-demand matching carried out in a business setting. The response will then focus on procuring the required relief items, whether from inside or outside the affected area. Finally, relief items need to be mobilized, stored, transported and distributed over the last mile to affected populations (Tatham et al., 2017). We have conducted a narrative review of the previous literature and identified a wide range of challenges to logistical activities at the operational level; see Table 1 for a summary.

Discussing needs assessment, Balcik and Beamon (2008) refer to the extreme unpredictability of demand in terms of disaster location, timing, type and size, which can create a bottleneck for logisticians trying to determine accurate numbers and needs in the affected population. L'Hermitte et al. (2015) discuss the cross-border logistical challenges and cross-border refugee movements that complicate needs assessment at the operational level. For instance, to estimate the needs of an affected population in Somalia, HAs had to operate remotely out of Kenya and other parts of Somalia. Furthermore, due to disruptions in communication infrastructure after a disaster, affected populations might not be able to articulate their needs related to culture and language (Kovács and Spens, 2011). Thus, the process of needs assessment or demand capture is vastly more challenging in the $\mathrm{HL}$ community than in the everyday business environment (Tatham et al., 2017).

As to procuring necessary supplies, it is difficult to obtain access to local markets and suppliers in areas with limited or no security, confronting HAs with the late delivery of supplies and time pressure arising from the urgent need for those supplies (Balcik and

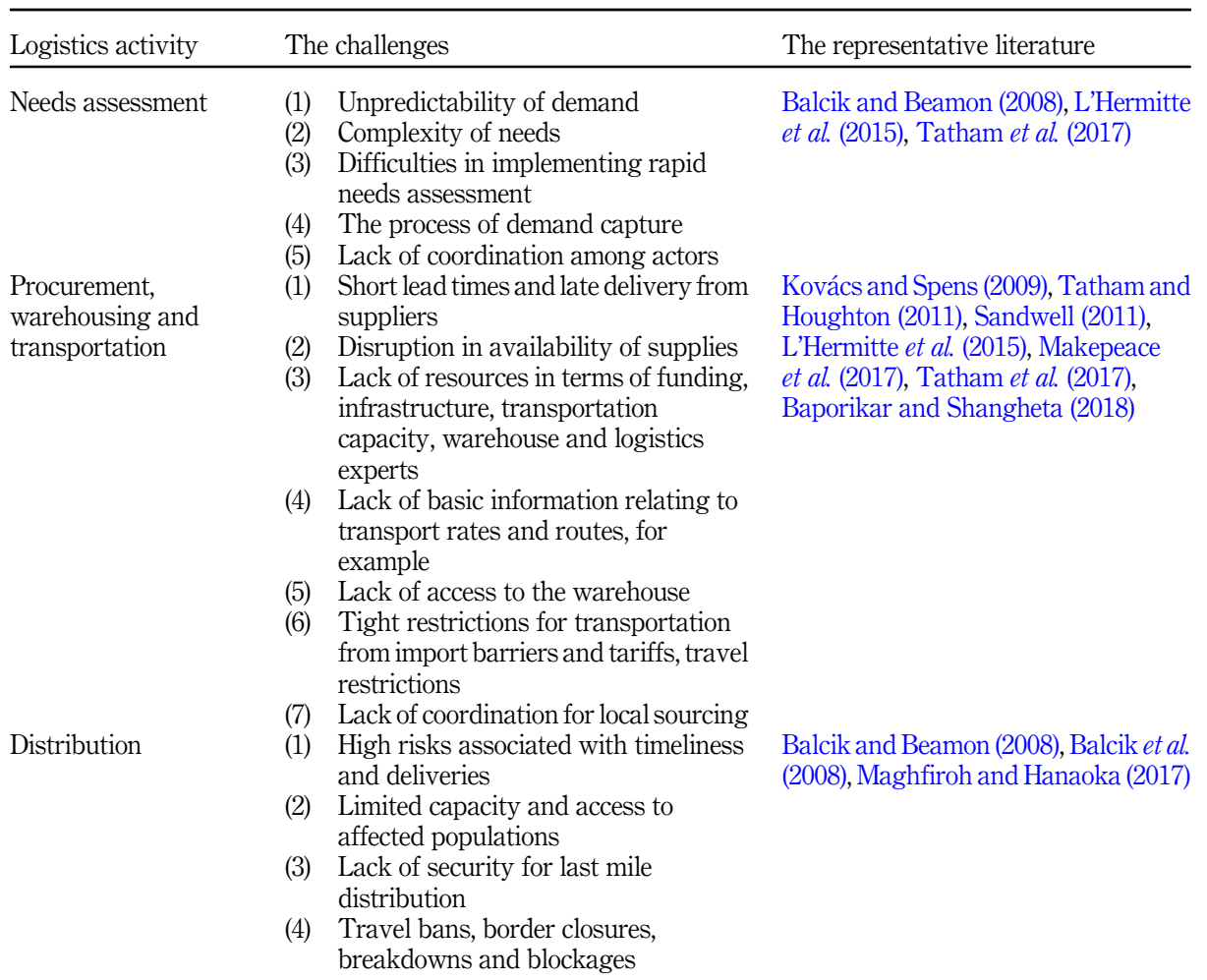

Challenges of $\mathrm{HL}$ in disaster relief operations 
JHLSCM 11,1
Beamon, 2008). Scarcity of resources like data and information, supplies, people, technology and transportation, along with inadequate infrastructure, warehouses and funding are but some of the many examples of operational constraints that add to the logistical challenges of the procurement, warehousing and last mile distribution of aid (e.g., Balcik and Beamon, 2008; Baporikar and Shangheta, 2018; Fritz Institute, 2004; Kovács and Spens, 2009; Makepeace et al., 2017; Sandwell, 2011). In Somalia, HAs lacked basic information relating to crucial items like transport rates, routes and mechanisms to move cargo from the port to their destinations. Because of Kenya's limited port capacity, there was congestion at Mombasa's port and late delivery of aid. Similarly, the movement of affected populations from one place to another can lead to changes in needs and logistics requirements such as supply chain remapping and a plan to increase storage requirements, adding another constraint for HAs that are already faced with limited resources in a highly competitive and vulnerable environment (L'Hermitte et al., 2015). Kovács and Spens (2009), studying disasters in Ghana, reveal the HL challenges from HAs' perspective as a lack of resources like funding, transportation infrastructure, early warning systems and warehouses. From a governmental perspective, limited supplies, vehicles and information technology are the primary challenges. Tatham and Houghton (2011) discuss Myanmar in the aftermath of the 2008 Nargis cyclone and report that international HAs had difficulty obtaining access to warehouses. Along the same lines, Kunz and Reiner (2016) refer to transportation regulation and government restrictions as the key HL challenges imposed on international HAs. These challenges can arise due to import barriers and tariffs, travel restrictions, border closures and excessive bureaucracy.

Normally, each of the many HAs responding to a disaster has its own organizational approach, with a distinct mission concept and relief operation structure. Thus, coordinating logistics activities at both the organizational and inter-organizational levels has been repeatedly reported as a factor that can impede the procurement of goods, warehousing and the last mile distribution of aid (e.g., Baporikar and Shangheta, 2018; Balcik et al., 2010; Fritz Institute, 2004; Kovács and Spens, 2009; Makepeace et al., 2017; Tatham et al., 2017). At the organizational level, poor communication and teamwork have been identified as factors that impede the work of program and logistics staff (Makepeace et al., 2017). The lack of HL standards and guidelines and inadequate training for logisticians have been cited as a factor decreasing the performance of inter-organizational collaboration efforts (Moshtari and Gonçalves, 2017).

The complexity of operations is another $\mathrm{HL}$ challenge, particularly with last mile distribution of relief supplies. HAs operate in an extremely complex humanitarian environment, with continuous supply chain disruption in the form of access limitations, capacity constraints and security concerns at the last mile. The nature of distribution is extremely dynamic, with frequent changes in routes and unpredictable road infrastructure. Yet, the last mile process poses the most significant challenges due to the travel ban, border closures, breakdowns and blockages (Maghfiroh and Hanaoka, 2017). In addition, relief supplies can be delivered from different locations, involving myriad local and international HAs. The distribution of scarce supplies with uncertain needs adds to the complexity of delivery processes. Finally, demand fulfilment depends heavily on the nature of a given disaster: type, impact, demographics, and social and economic conditions of the affected areas (Balcik et al., 2008).

Apart from logistical challenges, non-logistical challenges that are largely external to the focal organizations have been identified in the literature as directly or indirectly hampering the logistics of aid operations, including regulation and the role of social media and new emerging actors (see Table 2). First, the HL literature refers to problematic rules and regulations in the affected countries that influence humanitarian aid delivery (Kunz and Gold, 2017; Kunz and Reiner, 2016). Kovács and Spens (2009) identify a regulatory environment that could be challenging for HAs due to a lack of reliable governance and the absence of 


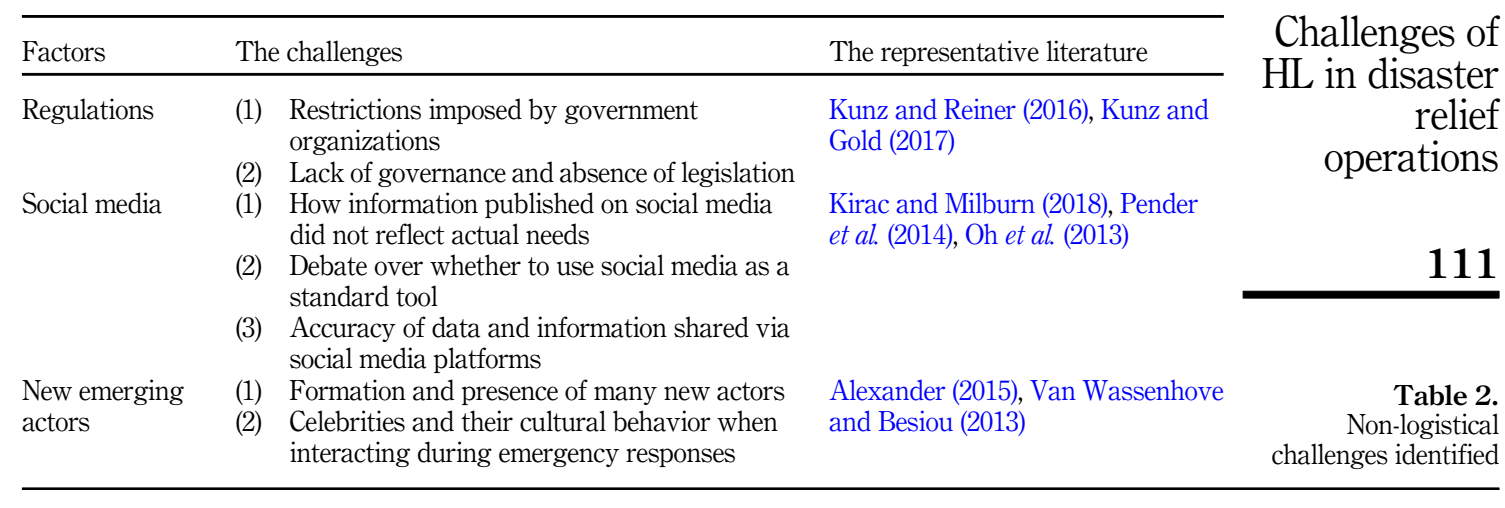

legislation during disaster relief operations. Part of Kovács and Tatham's (2009) study addresses the potential breakdown of the rule of law and national and international scrutiny through multiple forms of public and social media in disasters, all of which hinder the efficient and effective delivery of aid to affected populations. Given the powerful impact of national regulations on international and local HAs' entry to and level of engagement in humanitarian relief activities, this topic has not sufficiently explored.

Second, there is a growing literature on the benefits of social media in terms of its connectivity for rapid information sharing (e.g., Palen et al., 2009) and expressing emotional support for affected communities (e.g., Hughes et al., 2008). Indeed, HAs are becoming more reliant on social media platforms as a means of collecting, sharing and disseminating information before, during and after a disaster. Despite the benefits of social media (Houston et al., 2015; Wamba et al., 2017), several practitioners and scholars have expressed concerns about the potential challenges of incorporating social media into organizations, particularly HAs. For example, a large volume of content shared via social media might disrupt the supply chain and distract staff from work-related communications, leading to lower productivity (Barnawal, 2014; Leonardi et al., 2013). Likewise, the leakages of an organization's data and its dissemination to external actors via social media platforms could disclose confidential information and thus put the organization's intellectual property rights at risk. Furthermore, the provision of the right type and amount of assistance to beneficiaries affected by the 2010 Haiti earthquake was hampered by how information published on social platforms was used (Kirac and Milburn, 2018). Oh et al. (2013) determined the community-based information processing via Twitter using data from the three disaster situations of the Mumbai terrorist attacks in 2008, the Toyota recall in 2010, and the Seattle café shooting incident in 2012. The result showed that shared data and information with no clear and reliable sources was the most important rumor causing factor on Twitter in disaster relief operations. However, the use of social media in disaster situations is still in its early stages, and there is debate among HAs about whether to accept it as a standard sharing tool during disaster relief operations (e.g., Pender et al., 2014). Further research on the operational benefits and risks of social media will thus also be useful.

The third challenge influencing humanitarian aid delivery is the engagement of a high number of diverse actors, including emerging actors (e.g., Van Wassenhove and Besiou, 2013). The number of actors responding to highly mediatized disasters has increased substantially, as was demonstrated as long ago as the 2004 Indian Ocean tsunami relief operations (Besiou and Van Wassenhove, 2019). For instance, there were over a thousand new actors, each with different cultures and structures, operating in Haiti after the 2010 earthquake (Van Wassenhove and Besiou, 2013). While Alexander (2015) has examined the 
JHLSCM 11,1

\section{2}

role of celebrities and the impact of celebrity culture on the way people react to disasters, there remains a lack of research to more thoroughly investigate the role of new HAs and how they coordinate with more established HAs in disaster relief operations.

Overall, even though $\mathrm{HL}$ challenges have been studied extensively, further research is required to investigate non-logistics challenges at the national level, in particular as to rules and regulations, social media use and the emergence of new actors. Further research is required to understand the $\mathrm{HL}$ challenges in different contexts and then to implement tailored mitigation solutions (Kovács and Moshtari, 2019). This paper explores a practical approach to identifying the challenges of HL, particularly in cases where government agencies must coordinate with NGOs and new emerging actors like ad hoc groups and celebrities. This case study identified and discussed HL challenges related to the 2017 Kermanshah earthquake, where the humanitarian response was dominated by national actors, with international actors playing only a minor role, and the disaster affected a relatively small geographical region. In addition, the recency of the earthquake provides an opportunity to explore the operational implications of communication and information technology innovations like social media solutions in response operations, which have not yet been fully explored (Yan and Pedraza Martinez, 2019).

\section{Research methodology}

\subsection{Method}

The case study approach, which enables the collection of rich data, the in-depth exploration of a complex phenomenon (Stuart et al., 2002), and the identification of factors explaining that phenomenon (Voss et al., 2002) is appropriate for answering the present study's research questions. Given their high level of complexity, HL challenges must be investigated in their natural setting, and a case study allows for such an in-context analysis (Yin, 2009). The 2017 Kermanshah earthquake was selected as the case due to the numerous challenges during the disaster relief operations that were reported and mediatized by the organizations involved. The humanitarian response to the Kermanshah earthquake was largely carried out by national actors, with international actors playing only a minor role. Moreover, even though Iran is a disaster-prone area, few studies in humanitarian operations have collected and analyzed empirical data from Iran, meaning that its overall context is not as well understood as it should be, especially given its susceptibility to earthquakes in particular.

The main data sources are semi-structured interviews conducted with HAs involved in Kermanshah earthquake relief operations. In response to the disaster, some of the many groups of actors (government, private sector, local NGOs, international NGOs and social media activists) were directly engaged in HL; others were indirectly engaged through social media activism and community groups that were active in resource mobilization and last mile distribution (see Table 3). To obtain a comprehensive view of the response performance, we interviewed multiple informants in each group of actors by means of purposive sampling,

Number of interviews per humanitarian actor group

\begin{tabular}{lc}
\hline & $\begin{array}{c}\# \\
\text { Humanitarian actors }\end{array}$ \\
\hline Governmental organizations & 4 \\
International NGO (INGOs) & 6 \\
NGOs & 11 \\
Iranian Red Crescent Societies & 10 \\
Individual activists (e.g., owners of large channels in social media, academicians, private sector & 12 \\
and community group) &
\end{tabular}


covering actors governed by different mandates in various sectors, government officials, practitioners in the private sector and employees of local and international NGOs (see Appendix 1). The criteria for inclusion in the study were that respondents were knowledgeable and had been involved in the response to the Kermanshah earthquake. To contribute to the richness and variety of the data (Heckathorn, 1997), respondents with moderate to extensive experience (i.e., 15 years of experience in disasters on average) and in different positions (e.g., logistics officer, deputy head of relief, disaster relief manger and project manager) were selected from different sectors (i.e., provision of food, water, shelter, education and health services) using a snowballing technique.

A total of 43 face-to-face or telephone interviews were conducted. Background information that could identify individual interviewees is not included, as anonymity was a condition of participant involvement. However, information regarding organization type and mission, interviewee position, years of working experience and date of interview for each interviewee appears in Appendix 1.

The semi-structured interviews lasted an average of 60 minutes and included open-ended questions and probes to encourage detailed responses. Based on the initial literature review, an interview protocol was developed to provide a structure for the data collection process (see Appendix 2). The interview protocol was designed to capture HL activities, related logistical and non-logistical challenges, and the performance of the humanitarian response during the Kermanshah earthquake relief operations.

In analyzing the data, we applied an open coding procedure (Miles and Huberman, 1984) to identify and categorize HL challenges. We used a data reduction approach, coding data items that ranged in length from a few words to several paragraphs (Miles and Huberman, 1994). We were careful to code only those challenges related to HL that influenced HAs' performance due to specific actions and interactions rather than the personal views of the respondents. To connect our data to the existing literature (Eisenhardt and Graebner, 2007), the data were coded following a recursive (iterative) process in which data collection, data analysis and coding, and interpretation all occur throughout the study and thus influence one another (Willis, 2007).

The data coding was manually analyzed using a color-coded system through cross tabulations and tables in Microsoft Word. The transcripts were read through several times, with notes taken in tabular form. A set of codes and categories regarding the challenges was then defined and assigned to the text to identify when patterns appeared. The codes were linked to conceptual themes and used as a working template for the other transcripts. Then, the extracted themes were linked to the HL challenges identified in the literature, such as those associated with needs assessments, procurement, warehousing, transportation and last mile distribution. Two researchers analyzed the data. In order to reduce the possibility of bias, in a first step, each researcher separately summarized the challenges in the transcripts and recorded them in the tables. Challenges were highlighted in different colors to follow patterns throughout the transcripts. Then, a set of codes and sub-categories were defined, with similar logistical and non-logistical challenges grouped together. Each researcher applied the coding frame in consistent ways to insure intercoder reliability (O'Connor and Joffe, 2020). In the next step, the two authors compared their results and discussed the differences, overlaps and divergences within their analysis to reach a consensus (Thomas and Hardens, 2008). The codes were then linked to the conceptual or categorical themes identified in the literature review.

The researchers organized a seminar in July 2019, after data collection was complete and preliminary data analysis had been carried out, to present the project's findings. The forum was hosted by the Department of Industrial Engineering at Tarbiat Modarres University in Tehran; it lasted about three and a half hours. There were 25 participants; 12 had been interviewed beforehand, and the rest were academics. The results were presented, after which 
JHLSCM 11,1 participants shared their views on the results with the researchers. This event also allowed facilitated discussions among participants. The insights obtained during the seminar enabled the authors to further clarify their findings, ensure the trustworthiness of the qualitative data, and identify any misunderstandings or omissions (Voss et al., 2002).

\subsection{Case description}

On Sunday, November 12, 2017, a magnitude 7.3 earthquake occurred along the Iran-Iraq border, with its epicenter near Ezgeleh, Salas-e Babajani County, Kermanshah Province (Iranian Red Crescent Societies [IRCS], 2017). It was the world's deadliest earthquake of 2017; there were at least 630 fatalities and more than 9,000 injuries. A total of 427,266 people were affected in 8 districts of Kermanshah province. The earthquake seriously damaged 30,000 residential units in rural areas, while some cities were partially or completely destroyed (IRCS, 2017). In Sare-Pole-Zahab, some residents blamed the widespread destruction on poorquality construction. It was noted that older buildings remained standing, while many newer blocks collapsed, including hospital and health clinic structures (IRCS, 2018).

The Iranian government announced that the disaster had caused at least $€ 5$ billion in damage. During the response phase, basic needs were tents, blankets, clean water supplies and public sanitation facilities (International Institute of Earthquake Engineering and Seismology, 2017). As people from other provinces entered disaster-stricken areas during the recovery phase, the total population actually increased, which led to a quick shift in urgency from the necessities listed above to sewage overflows and other environmental issues. When the earthquake occurred, local HAs were of course under immense pressure to respond. There was no established mechanism through which the various not-for-profit, private, military and governmental agencies could coordinate their efforts or collectively identify the needs of the affected population (Ahmadi and Bazargan-Hejazi, 2018). Many community groups and new actors knew very little about how to respond to a disaster or how to collaborate to meet beneficiaries' requirements. This resulted in some areas like Sare-Pole-Zahab receiving a great deal of attention, while other affected populations living in remote areas struggled to survive with little support.

A sheltering emergency phase was rapidly completed in affected cities and villages. Emergency water, sanitation and hygiene supplies in affected areas were provided through coordination between the government, the IRCS, municipalities, the private sector and international NGOs. In addition, several other actors attempted to deliver aid directly to the affected populations. These actors preferred to use their own vehicles, travelling not only from neighboring provinces such as Hamadan but also from more distant areas like Tehran, Mashhad, Tabriz and Isfahan. Apart from domestic actors, a few international actors like the Government of Turkey, the European Union and The International Committee of the Red Cross offered and delivered aid (IRCS, 2017).

\section{Findings}

\subsection{Logistical challenges experienced during the 2017 Kermanshah earthquake relief operations}

Table 4 presents the HL challenges related to needs assessments, procurement, warehousing, transportation and last mile distribution of relief supplies implemented by HAs and their associated impact on supply performance during the 2017 Kermanshah earthquake relief operations. The table also provides representative quotes from the respondents.

The subsections below reveals the findings in detail for each $\mathrm{HL}$ challenge.

4.1.1 Needs assessment challenges. Our interview respondents cited several factors that impeded needs assessment procedures during the Kermanshah response. We have 


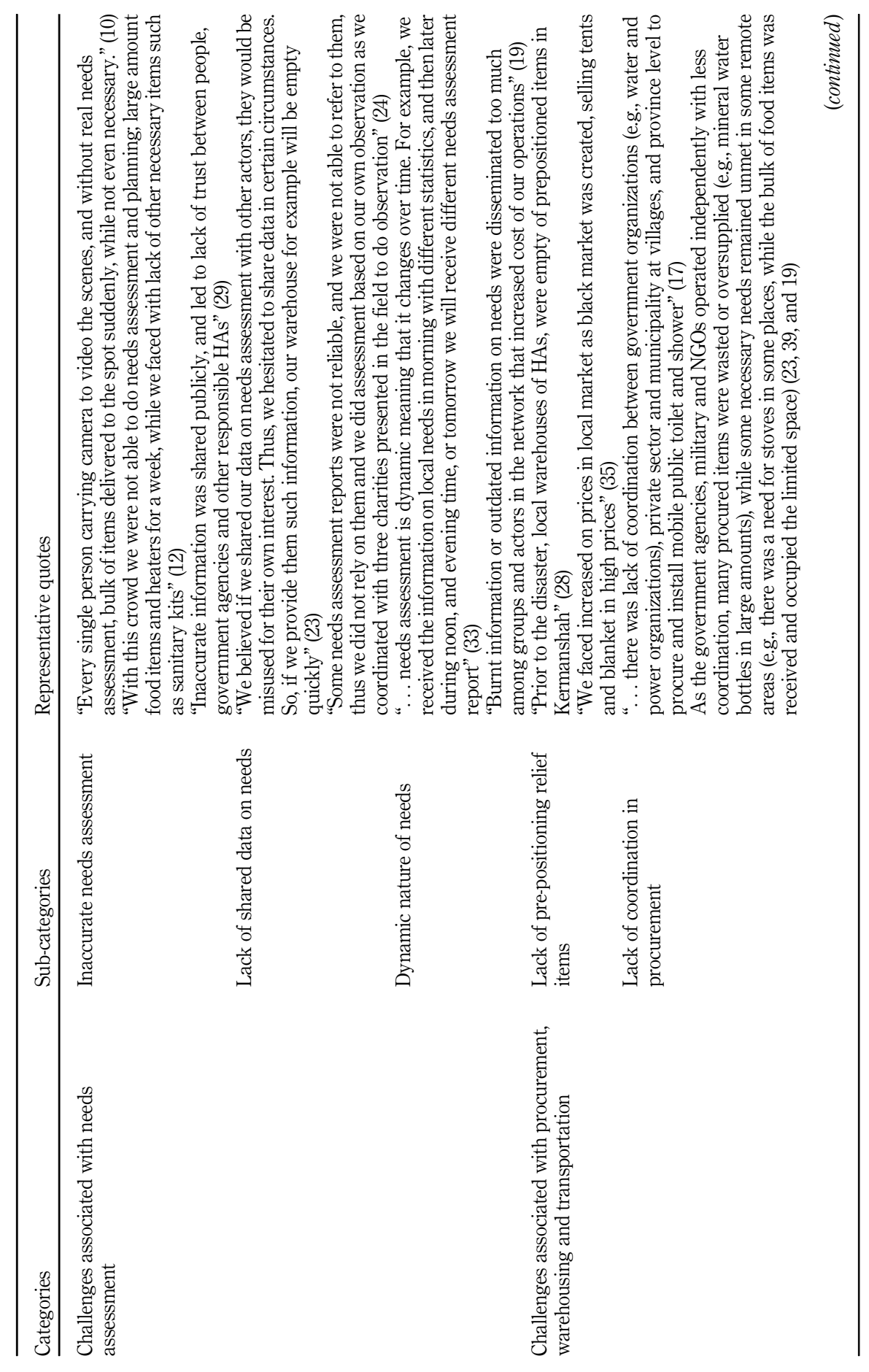

Challenges of $\mathrm{HL}$ in disaster relief operations

115

Table 4 Codes related to logistics challenges 
JHLSCM
11,1

116

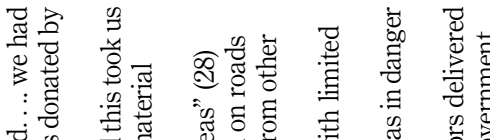

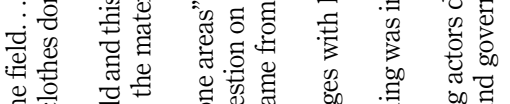

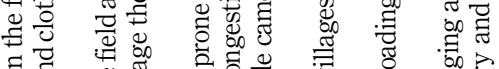 \\ : \\ 范

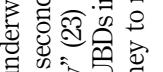

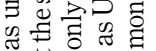

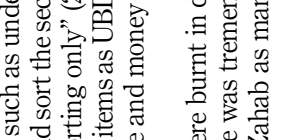

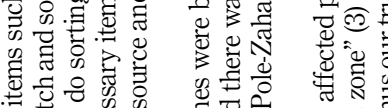 \\ 원

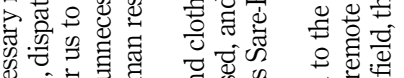

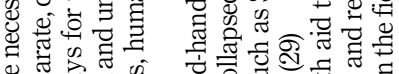

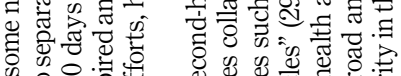

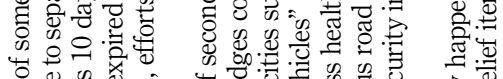

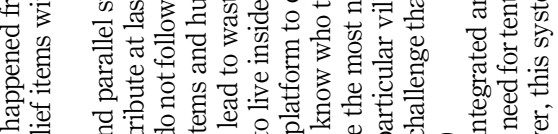

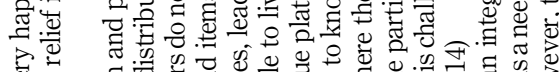

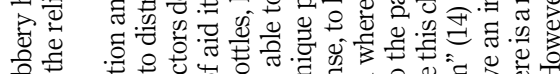

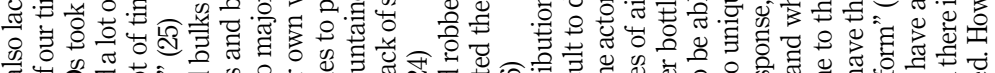

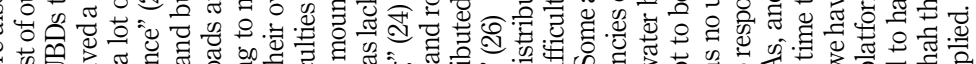

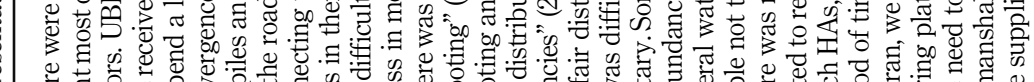

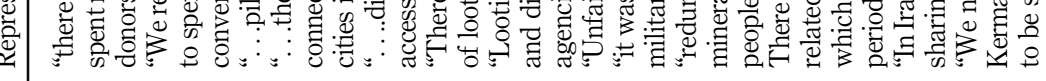

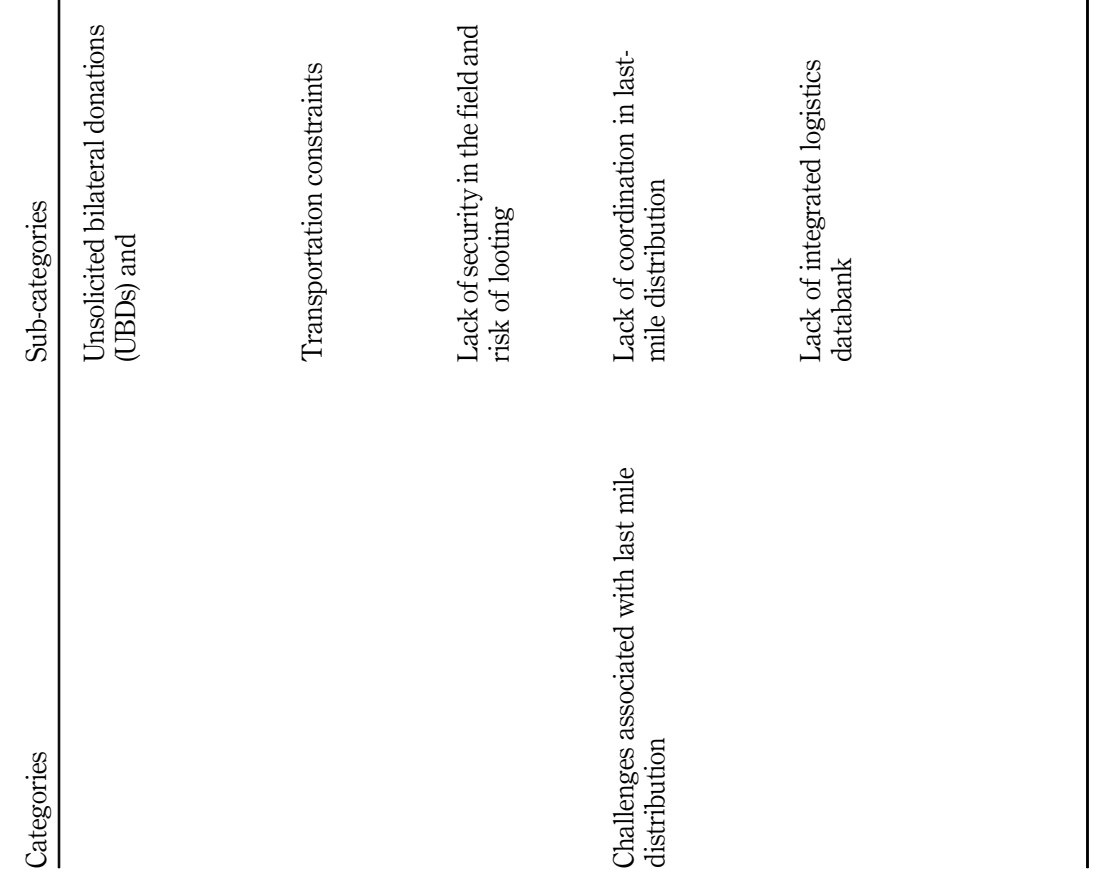


categorized them into three groups: inaccurate needs assessment, the lack of shared data on needs and the dynamic nature of the needs themselves. As to inaccurate needs assessment, respondent 10 reported that the humanitarian staff was too tired to complete a rapid needs assessment after being stuck in heavy traffic for an extended time. In addition, respondents 10 and 12 noted that the presence of many actors, some with no experience or expertise, led to the field delivery of large amounts of redundant items and materials because these actors had not carried out a proper needs assessment. As a result, there were reported instances of expired materials like mineral water and food being delivered and of some relief items not being distributed to the population for which they were intended (respondent 33). These actors also failed to capture the overall demand as determined by the cultural, lifestyle, demographic and geographic profiles of the affected populations. For example, there are three main ethnic groups in Kermanshah, and some actors failed to understand the actual needs of each group (respondent 41).

Second, respondents noted a lack of data and information sharing on needs assessment. Some respondents reported difficulty in accessing information on needs from other actors and thus relied on their own needs assessments. Due to disruptions in the communication infrastructure, they could not even share their own information on needs with other actors, although they were able to share the information among their own members. As access to remote areas was difficult, even local and state authorities could not assess the needs of those affected by the disaster in these areas (respondent 19). Some argued a joint needs assessment could help mitigate the challenges caused by the lack of shared data. For instance, respondents 15 and 16 agreed on the importance of executing a joint needs assessment with other HAs in the relief network. This assessment could be done in coordination with NGOs, international NGOs, local community groups, military units and ad hoc groups. However, respondents 24 and 29 cautioned that a lack of trust among these actors could hinder the effectiveness of a joint needs assessment and subsequent information sharing.

In the Kermanshah disaster, local experience and local actors were reported to be the main sources of information on needs, as respondent 26 put it:

We did a joint needs assessment at the field level in coordination with our own team and local communities. We were in fact a source of reliable information for other NGOs and volunteers who aimed to deliver aid at the last mile. We have been working in Kermanshah for 12 years; therefore, we have local experience with and knowledge about the region.

Finally, as to the dynamic nature of needs, some respondents mentioned the challenge created by the evolving nature of what was required and referred to the merits of an iterative needs assessment process running from initial response to the recovery phase. Respondent 33 said that "needs assessment is dynamic, meaning that it changes over time. For example, we received the information on local needs in the morning with statistics; later, at noon and in the evening or the next day we would receive a different needs assessment report." Other HA representatives noted difficulties in receiving updated and accurate information on needs.

4.1.2 Procurement, transportation and warehousing challenges. HAs normally pre-position relief items in established warehouses. However, constraining factors such as funding may prohibit the completion of such efforts before a disaster occurs: "Prior to the disaster, local HA warehouses were empty of pre-positioned items in Kermanshah" (respondent 28). Coordination among HAs and ad hoc groups was a major obstacle in post-disaster procurement actions. For instance, respondent 17 noted that the lack of coordination between government water and power organizations, municipalities and the private sector delayed the installation of sanitation facilities for affected populations. In other cases, the direct involvement of civilians and ad hoc groups in the distribution of relief items disrupted the supply chain for unsolicited bilateral donations (UBDs), as these actors were not able to unpack and sort the items to meet the affected populations' needs.
Challenges of $\mathrm{HL}$ in disaster relief

operations 
JHLSCM 11,1

118

Transportation was another significant HL challenge that HAs faced during the earthquake relief operations. Some roads and bridges had collapsed, and there was tremendous congestion on roads connecting to major centers like Sare-Pole-Zahab. The traffic jams were exacerbated by the presence of multiple actors coming from other cities in their own vehicles, according to respondent 29. One solution to the traffic issues was air transportation, which was costly but enabled quicker delivery of relief items and the transport of injured people to the capital city's hospitals in cases where local hospitals had collapsed.

Another problem was theft. A significant number of items were stored in local warehouses, and some were stolen due to poor security. Shared warehouses had been implemented in coordination with religious teams and ad hoc groups that did not have security teams. Unsecure places such as mosques, schools, residential yards and mobile containers were used as warehouses in disaster-stricken areas (respondents 23 and 28).

4.1.3 Challenges with last mile distribution. The final distribution of relief items requires logisticians to overcome the impediments of a degraded physical infrastructure and communications system. After the Kermanshah earthquake, the last mile delivery of relief items to the affected populations was disrupted by several key factors. First, HAs did not coordinate their aid delivery plans and duplicated some activities, assisting the same groups of people and leaving others without any support. Second, there were cases in which some HAs prioritized helping their own relatives and neighbors. These factors led to inequitable and unfair distribution, as described by respondent 28 :

Organizations and ad hoc groups gave priority to their own relatives and family members. Then they went for other villages and communities. This led to the presence of those people who had not received aid and came and jumped into the trucks.

In addition, HAs could not control crowds in some instances, and some people jumped on trucks to take tents and blankets, which deprived the elderly population of receiving that aid, according to respondent 27 . Furthermore, as the government agencies and NGOs operated in an independent, uncoordinated fashion, many procured items were wasted or oversupplied, while other needs remained unmet in some remote areas. For example, respondents 23 and 39 reported that some areas did not receive stoves for heating because the bulky food items they received filled the limited storage space. While the IRCS was authorized to provide last mile delivery, several unauthorized NGOs and ad hoc groups provided last mile support without coordinating with the IRCS relief team (respondent 5). These groups also distributed items that varied in terms of brand and quality in the same region, creating a problem for the HAs because it raised the beneficiaries' expectations of and requests for high-quality products, as noted by respondent 27 .

Second, relief item distribution delays were reported due to the lack of an integrated logistics databank. The relief effort as a whole had no way to track the distribution of relief items during disaster response and recovery, according to respondent 28. Respondents agreed that no single platform existed to provide official data related to the response, to identify actors, to record the types of aid provided by different HAs, or to determine which areas most needed aid and what type of aid was needed during a specific period. By contrast, respondent 25 noted that the coordination between NGOs and military teams was efficient and reliable. The respondent 25 reported the following:

We did final distribution points inside the military camps and had mixed genders for the final distribution, as within Muslim communities' women prefer to be served by the same gender. We, therefore, received a shared and secure warehouse that saved us the warehousing cost. 


\subsection{Non-logistical challenges identified during the 2017 Kermanshah earthquake relief operations}

The analysis of our data revealed three non-logistics challenges influencing humanitarian response: social media use, regulations and the emergence of new actors (see Table 5). These factors have rarely been analyzed by prior studies, but their potential impact on humanitarian operations - and the likelihood that at least social media use and new actors will grow in significance - demands more academic attention.

4.2.1 Growing use of social media. During the Kermanshah earthquake, social media platforms like Telegram and Instagram were beneficial, despite certain inherent drawbacks. The use of social media platforms helped HAs mobilize local, national and international support for the affected populations, facilitating immediate assistance for thousands. Social media also enabled victims, friends and families to share valuable and timely information. This proved to be of immense help in rescue and relief efforts for those affected, as one respondent noted: "We could connect to local communities and identify their needs quickly" (respondent 16). In addition, social media helped some individuals and community groups post links to receive donations that funded assistance for earthquake victims. Social media use was particularly important given that, as respondent 24 indicated, it prompted numerous volunteers, local and non-local civilians, and community groups to participate in delivering aid.

Social media was also employed as a tool for sharing information on weaknesses in HA operations during the response to the earthquake. These deficiencies were underscored across networks, ultimately prompting the involvement of military and state authorities. For example, respondent 39 revealed that news of the delivery of expired commodities published across social networks led to the turnover in the humanitarian staff - even in some senior positions - at the NGOs and government agencies responsible for disaster relief. Indeed, two IRCS disaster relief managers were fired within 72 hours of the earthquake. The corrective spotlight was also directed at an NGO that failed to satisfy demand in a small village in Sare-Pole-Zahab. Following online criticism, many blankets, tents and water supplies were delivered rapidly to that location, with the deliveries exceeding the entire village's requirements by $75 \%$. As observed by respondent 4 , while social media reports uncovered the unfair distribution of tents among disaster-stricken individuals, they also prompted the distribution of items on a scale far beyond what a specific affected population needed:

It was rumored around social media that one affected family did not receive shelter in a village. This led to negative feedback and reputation for the responsible HOs providing shelters and the escalation of tent supplies in excess of needs (respondent 19).

4.2.2 Regulations on the roles and involvement of HAs. Our study reveals an absence of regulations to define the roles and involvement of ad hoc groups in disaster relief operations and to ensure coordination with established HAs' supply chains. While such groups have extensive capacity in terms of logistics in areas like transportation, volunteer manpower and funding, the respondents agreed that strict regulation of their involvement is needed. After the Kermanshah earthquake, some actors - government agencies, military teams, smaller NGOs, among - misused the information on needs obtained by other actors like the IRCS. In some cases, HAs shared information with other actors over public or social media, and competitors like NGOs used that information for their own benefit. In one instance, a temporary warehouse used by larger HAs was soon emptied of vital supplies because a large number of new actors descended on the warehouse due to an information disclosure. In another example, respondent 23 stated that if NGOs were to provide transport schedules and reporting containing needs and support, government agencies may cease funding because of suspected fraud and questions about how and from what source the budget and items were procured and for whom they were intended. Furthermore, some local community
Challenges of $\mathrm{HL}$ in disaster relief

operations 
JHLSCM
11,1

120
Table 5.

Non-logistical challenges identified during disaster relief operations

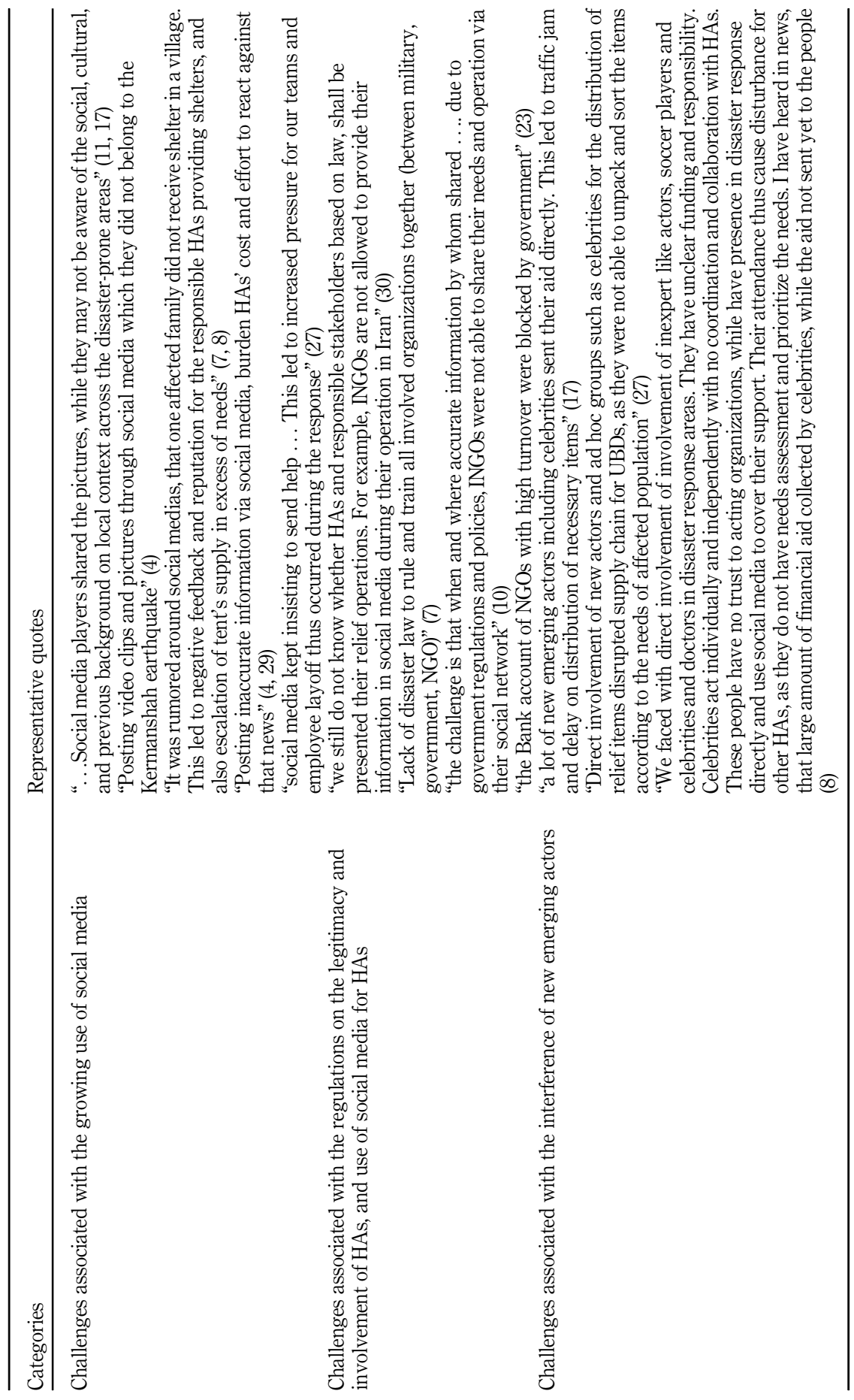


groups, ad hoc groups and celebrities took advantage of larger NGOs' brands and logos for their own purposes, receiving more volunteers and funding.

Many fundraising campaigns were established immediately after the disaster. Some were unauthorized, as they did not register through Iran's Ministry of Interior and were not under government control. Although these entities could deliver aid to the affected populations, respondents 26 and 32 noted that established HAs such as the IRCS and other NGOs did not trust them to cooperate and jointly mobilize their resources.

A small number of HAs, including international NGOs, were forced to restrict sharing information on their activities, requirements and relief operations to internal channels due to government regulations that prohibited them from publicly sharing such information. In fact, international humanitarian actors (IHAs) were not authorized to participate in disaster relief operations in Iran beyond coordinating with government authorities on matters related to refugee settlement and food security. Respondents 10 and 35 indicated that IHAs are mainly responsible for providing support to refugees living in their home country. These kinds of restrictive policies can suppress the capabilities of IHAs and their logistical capacity to engage with other HAs during disaster relief operations.

Overall, respondents reported a failure on the part of government agencies to exercise control and auditing to establish basic rules and principles for information sharing, logistical procedures and the roles and responsibilities of each actor within the HA network. Other potentially useful policies and protocols exist but were not approved before the Kermanshah earthquake; for example, according to respondent 21, procedures for establishing an integrated logistical databank system and promoting information technology development had been written but were still under review by government bodies before they could be implemented by certain HAs like the IRCS.

4.2.3 Interference of new actors. During the Kermanshah earthquake relief operation, numerous celebrities acted as intermediaries between donors and beneficiaries. These individuals engaged in little or no coordination with the various HAs in the field, using their own supply chains instead. Celebrities such as athletes, actors, politicians and even university professors called on their fans and followers to deliver aid directly during disaster relief operations. These people were not trusted by the HAs but still received large amounts of funds, according to respondents 7 and 8. Respondent 33 noted that some relief workers agreed that the direct involvement of celebrities in logistics activities with almost no coordination or cooperation with government agencies or HAs was actually a lose-lose proposition for both parties in terms of resources used and raising beneficiaries' expectations, as their presence in the field created logistical bottlenecks for HAs. For example, respondent 30 indicated that celebrities did not conduct proper needs assessments or recognize the oftenunhelpful outcome of their actions in the affected areas:

Some celebrities like Mahnaz Afshar [an Iranian cinema and television actress active since 1998] used Twitter to announce needs, and then we observed large numbers of sanitary items such as diapers and sanitary pads distributed to the disaster-stricken areas, more than was needed and in large volumes exceeding demand.

In some cases, the celebrities did not send the items and money collected to the field or were unable to do so because the government barred their involvement and froze their bank accounts. Often, the pooled donations and mobilized resources went to waste, either in the capital of Tehran or in Kermanshah itself.

In addition, respondent 15 advocated that, since celebrities were not logistically capable of handling the procurement, mobilization and transportation of relief items, they should coordinate with the HAs operating in the field, such as by using the IRCS supply chain. Furthermore, successful coordination between NGOs, international NGOs and celebrities 
JHLSCM 11,1

could be facilitated by Iran's National Disaster Management Organization (NDMO). Respondent 30 pointed out the problems that resulted from not having this coordination:

There was a lack of coordination between celebrities and the IRCS. For example, Ali Daei, one of the greatest Iranian football players in the world, arranged to import two shipping containers of powdered baby milk from Germany. While it had faced problems due to tariff and custom clearance issues - apart from the sanctions imposed by the US - the IRCS helped them to release the containers and deliver them to Kermanshah; however, that amount of baby milk powder was not required, and the expiration date was about to occur.

Many new actors - ordinary individuals, celebrities and representatives from other communities - visited the site immediately after the quake to deliver aid. This influx of individuals into the province was clearly motivated by a desire to help, but it also led to an increase in temporary dwellers in major villages and cities already burdened by the disaster. The HAs whose operations were observed for this study all confirmed that the massive ingress and engagement of ordinary individuals in the field created operational difficulties due to congestion along the roads connecting the most severely devastated areas and thus had a negative impact on HA performance.

\section{Discussion}

The results of the qualitative data analysis in this paper lead to several conclusions. First, the $\mathrm{HL}$ challenges accord with and, in some cases, expand on previous findings in the $\mathrm{HL}$ literature (Kovács and Spens, 2009; Kovács and Tatham, 2009; Leiras et al., 2014; Sandwell, 2011). Needs assessments, for instance, were identified in this study as an especially critical issue, confirming previous findings (e.g., Balcik and Beamon, 2008; L'Hermitte et al., 2015; Tatham et al., 2017). The process of demand capture within the HL community was noted to be considerably more difficult than demand capture in the business context (Tatham et al., 2017). Indeed, inaccurate and ineffective needs assessments conducted by HAs, particularly by emerging actors, can negatively impact performance by delaying relief item procurement, fostering the distribution of unnecessary items, creating redundancies in resources and increased oversupply costs, occupying warehouse space with items already procured, and causing inequitable aid distribution to affected populations.

The lack of coordination between the network of actors, particularly between established HAs and new actors, coupled with mistrust among HAs and the impact of devastated infrastructure, creates challenges for relief item procurement, warehousing and transportation within disaster-stricken areas. This finding confirms reports in previous studies such as Baporikar and Shangheta (2018), Balcik et al. (2010), Fritz Institute (2004), Kovács and Spens (2009), Makepeace et al. (2017), Tatham et al. (2017), and Kunz and Reiner (2016). These obstacles delay procurement, increase costs due to oversupplying, cause shortages of some necessary items, raise warehousing costs, and extend lead times. Based on the statements of the respondents, the failure of established HAs to pre-position commodities prior to the Kermanshah earthquake led to stockout costs, increased lead times, unmet demand capture and higher costs of procuring commodities because the HAs were forced to make purchases on the black market. Security problems were another challenging issue that occurred during the 2017 earthquake disaster relief operation; it led to increased costs from the need to replace stolen items. The findings here confirm the importance of ensuring safety and security during a crisis, as established in studies such as L'Hermitte et al. (2015).

Finally, the lack of an integrated HL logistics databank and standards at the local and national levels made it difficult for HAs to track the delivery of aid, which increased their supply and distribution costs because they were not aware of what actors were present, what capacity these actors had, or which types of aid they were providing. While attempts have 
been made in the past to resolve the databank issue, many HAs still struggle to achieve the optimal end-to-end visibility for their supply networks in a real-time and open-source format (e.g., Tatham et al., 2017; Makepeace et al., 2017). These findings also complement frequently reported concerns about a lack of standards, training and guidelines in HL (Fritz Institute, 2004; Kovács and Spens, 2009; Sandwell, 2011).

Besides the HL challenges listed above, our exploratory study revealed another set of issues, i.e., non-logistical challenges, influencing humanitarian response efforts: the growing use of social media, an absence of regulations on the legitimacy and involvement of HAs, and the interference of new actors. There is scant literature providing insight into these factors or elaborating on their operational implications (e.g., Kunz and Reiner, 2016; Kovács and Spens, 2009; Kirac and Milburn, 2018; Besiou and Van Wassenhove, 2019; Lewin et al., 2018), and future studies may help understand them and find solutions to lessen their impact on humanitarian response operations.

In addition, our findings reveal that the heavy use of social media by HAs, particularly new actors, resulted in large volumes of unstructured data and content being produced and disseminated through social networks. That content spread virally, encouraging newcomers to become involved. This brought many of these individuals and groups into the field, causing traffic jams and other supply chain bottlenecks. In terms of logistics, social media disrupts supply chains through inaccurate needs assessments that result from the large volume of unstructured data and content, redundancies in unnecessary items due to the presence of many emerging actors, shortages of storage space and greater procurement expenses due to higher prices.

Poor or nonexistent implementation of governmental regulations and policies created challenges in the response to the Kermanshah earthquake. Similar findings have previously been reported in studies of other disasters (e.g., Baporikar and Shangheta, 2018; Kovács and Spens, 2009). The results of the present study reveal that the organizations most culpable for not enforcing regulations during the Kermanshah relief operations were government agencies. Problems such as a lack of international NGO operational visibility due to government restrictions, the absence of a policy regarding the engagement of new actors, and the lack of external auditing and control over logistics activities were all problems in this category. Furthermore, the extremely lengthy bureaucratic procedures involving international NGOs and government agencies such as the Ministry of Foreign Affairs, NDMO in the Ministry of Interior, and the Bureau for Aliens and Foreign Immigrant Affairs hindered effective coordination and cooperation between these parties and led to reduced amounts of funding and in-kind aid from international donors and agencies.

Finally, the emergence of new actors in the Kermanshah earthquake was overwhelming and challenging, as these actors had poor logistics capabilities, occupied vital storage space, consumed scarce resources, and contributed to the inequitable distribution of relief items. Many respondents reported inefficient UBD use and oversupply costs. Research on the emergence of new actors in disaster relief operations and the management of their engagement remains scant in the HL literature (Lewin et al., 2018; Van Wassenhove and Besiou, 2013).

\section{Academic contribution and managerial implications}

The purpose of this paper was to extend the understanding of $\mathrm{HL}$ challenges with respect to the findings in previous studies by answering the following research questions: (1) What were the key challenges in disaster relief operations in the 2017 Kermanshah earthquake? and (2) What were the critical challenges in the 2017 Kermanshah earthquake that influenced disaster relief operations but have not been extensively explored in previous studies?
Challenges of $\mathrm{HL}$ in disaster relief

operations 
JHLSCM 11,1

The findings suggest that humanitarian logisticians deal with multiple challenges during disaster relief operations. One group of challenges is related to HL (i.e., needs assessment, procurement, warehousing, transportation and distribution) and has been discussed extensively in the literature. Other influences on the performance of $\mathrm{HL}$ activities are the growing use of social media, regulations associated with aid delivery, and the engagement of new humanitarian actors such as social media activists and celebrities. These factors have not been extensively examined in the literature and - given their critical influence on HAs' performance - require much more scholarly attention. These issues all contributed to disruptions of the established HAs' supply chains and thus negatively affected the supply performance of actors during disaster relief operations in Kermanshah. These effects included transportation delays, long lead times for last mile distribution, duplication of efforts and redundancies, and the inequitable distribution of relief items to affected populations. In overall, this research contributes to the body of HL literature in terms of categorization of both operational and nonoperational challenges. In terms of logistics, challenges connected to needs assessment were identified (including the sub-categories of inaccurate needs assessment, lack of shared data on needs and the dynamic nature of needs), procurement, warehousing and transportation (including sub-categories of the lack of prepositioning relief items, lack of coordination, UBDs, transportation constraints and lack of security in the field and risk of looting). While prior studies have revealed most of these challenges, the overall research result is fragmented. Therefore, this categorization and sub-categorization denoting the logistics challenges could provide further detailed explanations. Moreover, other challenges including the growing use of social media, regulations on the legitimacy and the use of social media for HAs, and interference of new emerging actors, during disaster relief operations have been explored and identified in this research.

Practitioners suggested strategies to mitigate the risk of poor implementation of regulations. For example, the disaster management authorities at the governmental level felt that there should be a working group that engages key actors like national and international NGOs, community leaders and committed celebrities to establish the rules of engagement for multiple actors in disaster response contexts. In particular, more formal coordination meetings need to occur between government agencies, international NGOs and UN agencies to determine rules and encourage the involvement of international actors to shorten the timeframes of administrative procedures.

The strategies recommended by practitioners to mitigate the risk of social media challenges are varied in terms of identifying the roles and responsibilities of social media players and activists from the preparedness phase prior to disasters throughout the entire disaster management cycle. Additionally, HAs need to increase their basic knowledge of how to incorporate social media into their logistics activities and standard operating procedures around sharing information about needs, procurement, transportation schedules and both intra- and inter-organizational coordination. The development of standard practices on the use of social media could provide additional support to HAs in disaster relief operations; more regular training on how to use social media platforms may be required for disaster management organizations. Finally, government agencies like Iran's NDMO should establish themselves as leaders in coordinating and connecting new and established HAs. Indeed, this study's results suggest that an effective coordination unit should be established to deal with new actors and thus increase the speed of operations.

\section{Limitations and further research}

This study has several limitations. First, insights from a single case study may not be generalized through abstraction and the attendant loss of context, but they may be applicable to other situations through reflection on similarities and differences between contextual 
factors (Greenwood and Levin, 2007). While examining a single case study limits the transferability of findings, it offers convincing insights, particularly when the situation (i.e., a disaster response) is deliberately selected to provide certain contributions that alternative cases may not reveal (Siggelkow, 2007). This case study identified and discussed HL challenges related to the 2017 Kermanshah earthquake, and the lessons learned from that experience might apply to other contexts, regions and disaster types. The results could be particularly cogent in contexts where the humanitarian response is effectively dominated by national actors, with international actors playing only a minor role in operations, and in situations where the disaster affects a relatively small geographical region, meaning that a large number of HAs will compete for media visibility and local resources. Future studies should collect their own empirical data to test the generalizability of the challenges discussed here and assess their impact in other contexts.

Second, the data collection in this explorative study was based on a set of semi-structured questions, not a set of measures or statements with which informants could specify a level of agreement; therefore, we were not able to provide the number of respondents who agreed with a particular statement. Future studies may assess these findings though large-scale surveys and compare the perceptions of people associated with HAs.

Third, this paper uses an explorative case study method intended to identify and elaborate on the challenges that HAs faced in a recent natural disaster in a developing country. It did not seek to further develop theory, but future studies may explore and provide theoretical explanations of the role and impact of challenges such as the growing use of social media, the emergence of new actors, and regulating the performance of HAs.

In addition to the findings gleaned from this analysis, some points of interest extracted from the case study merit further research. The first is the inaccurate needs assessment procedures that lead to the distribution of unnecessary items, resource redundancies, and higher costs for HAs' UBDs and warehousing. While the Geneva-based Inter-Agency Standing Committee has developed a complete set of standards for needs assessment procedures for HAs, policy specialists and decision-makers should take note that difficulties in conducting an effective needs assessment translate to a lack of in-country preparedness. Conducting coordinated needs assessments might be one solution to improve the efficiency and effectiveness of logistics services, but the issue of trust among HAs needs to be considered (Tatham and Kovács, 2010), and there must be a clear understanding of the dynamic nature of needs assessments. Considering the importance of joint needs assessments, further research is needed on the topic in the context of $\mathrm{HL}$, along with additional research on policy support for HAs regarding when and how data on needs should be shared during disaster relief operations.

The second point of interest is the lack of logistics coordination, relief item pre-positioning, and supply chain security that hinders effective and efficient delivery of aid to affected populations. Just as these challenges can be exacerbated by the lack of a national integrated logistics databank, these deficiencies result in performance pitfalls such as oversupply, unfair distribution, stockouts, the need to repurchase goods and poor transparency regarding supply chain tracking and tracing. This point reinforces the need for more and better educational programs for local and national humanitarian logisticians on an effective reliefitem and services pre-positioning structure and for improved security for staff and goods during relief operations. Indeed, security is a key element of any successful response. Thus, further studies should help develop a framework for security elements across supply chains that connect multiple actors, including the military, government agencies and NGOs.

The third point of interest is the lack of clear regulation or legislation supporting international NGOs and their engagement with local and national HAs. Considering the lengthy bureaucratic procedures between international NGOs and national authorities in
Challenges of $\mathrm{HL}$ in disaster relief

operations 
JHLSCM 11,1

Iran, further research is needed on government policy support for national disaster preparedness through coordination mechanisms that involve IHAs.

In addition, and as noted above, the emergence of new actors shows no sign of slowing. Some of these actors have thousands or even millions of followers of their social media presence. While they can support aid delivery through resource mobilization and fundraising, they can also disrupt other HA supply chains by failing to coordinate with the other actors in a network. Therefore, further study is recommended on the involvement of new HAs and policy support to better prepare this emerging group. Further studies are also needed to explore effective and efficient ways for established HAs such as the IRCS to interact and coordinate with new HAs.

\section{References}

Ahmadi, A. and Bazargan-Hejazi, S. (2018), “2017 Kermanshah earthquake: lessons learned”, Journal of Injury and Violence Research, Vol. 10 No. 1, pp. 1-2.

Alexander, D. (2015), "Celebrity culture, entertainment values and. . . disaster”, in Krüger, F., Bankoff, G., Cannon, T. and Schipper, L. (Eds), Cultures and Disasters: Understanding Cultural Framings in Disaster Risk Reduction, Routledge, London, pp. 179-192.

Balcik, B. and Beamon, B.M. (2008), "Facility location in humanitarian relief", International Journal of Logistics Research and Applications, Vol. 11 No. 2, pp. 101-121.

Balcik, B., Beamon, B.M. and Smilowitz, K. (2008), "Last mile distribution in humanitarian relief", Journal of Intelligent Transportation Systems, Vol. 12 No. 2, pp. 51-63, doi: 10.1080/ 15472450802023329 .

Balcik, B., Beamon, B.M., Krejci, C.C., Muramatsu, K.M. and Ramirez, M. (2010), "Coordination in humanitarian relief chains: practices, challenges and opportunities", International Journal of Production Economics, Vol. 126 No. 1, pp. 22-34.

Baporikar, N. and Shangheta, L.B. (2018), "Challenges facing humanitarian logistics in a nonprofit organization”, International Journal of Applied Logistics, Vol. 8 No. 1, pp. 35-56.

Barnawal, N. (2014), "Social media in supply chain: the new trend", available at: http://www. infosysblogs.com/oracle/2014/01/social_media_in_supply_chainth.html (accessed 2 October 2020).

Besiou, M. and Van Wassenhove, L.N. (2019), "Humanitarian operations: a world of opportunity for relevant and impactful research", Manufacturing and Service Operations Management, Vol. 22 No. 1, pp. 135-145, doi: 10.1287/msom.2019.0799.

Bölsche, D., Klumpp, M. and Abidi, H. (2013), "Specific competencies in humanitarian logistics education", Journal of Humanitarian Logistics and Supply Chain Management, Vol. 3 No. 2, pp. 99-128.

Eisenhardt, K.M. and Graebner, M.E. (2007), "Theory building from cases: opportunities and challenges", Academy of Management Journal, Vol. 50 No. 1, pp. 25-32.

Fritz Institute (2004), "Humanitarian logistics conference-Africa region 2004", available at: http:// www.fritzinstitute.org/prgSC-HLCaf2004-proceedings.htm (accessed 2 October 2020).

Greenwood, D. and Levin, M. (2007), Introduction to Action Research: Social Research for Social Change, SAGE, Thousand Oaks, CA.

Gustavsson, L. (2003), "Humanitarian logistics: context and challenges", Forced Migration Review, Vol. 18, pp. 6-8.

Heckathorn, D.D. (1997), "Respondent-driven sampling: a new approach to the study of hidden populations", Social Problems, Vol. 44 No. 2, pp. 174-199.

Houston, J.B., Hawthorne, J., Perreault, M.F., Park, E.H., Goldstein Hode, M., Halliwell, M.R., Turner McGowen, S.E., DavisVaid, R.S., McElderry, J.A. and Griffith, S.A. (2015), "Social media and 
disasters: a functional framework for social media use in disaster planning, response, and research", Disasters, Vol. 39 No. 1, pp. 1-22.

Hughes, L.A., Palen, L., Sutton, J., Liu, B.S. and Vieweg, S. (2008), "Site-seeing in disasters: an examination of on-line social convergency", 5th International ISCRAM Conference, May 4-7, 2008, Washington DC, USA.

International Institute of Earthquake Engineering and Seismology (2017), Sare Pol Zahab Earthquake Report, 5th ed., Tehran.

Iranian Red Crescent Societies (IRCS) (2017), "Kermanshah earthquake-Iran: operations update 2", available at: https://reliefweb.int/report/iran-islamic-republic/kermanshah-earthquake-iranoperations-update-2 (accessed 2 October 2020).

Iranian Red Crescent Societies IRCS (2018), "Information bulletin: Iran earthquake", available at: https://www.ifrc.org/docs/Appeals/18/IB_IR_26.11.2018.pdf (accessed 2 October 2020).

Kirac, E. and Milburn, A.B. (2018), "A general framework for assessing the value of social media for disaster response logistics planning”, European Journal of Operational Research, Vol. 269 No. 2 , pp. 486-500.

Kovács, G. and Moshtari, M. (2019), "A roadmap for higher research quality in humanitarian operations: a methodological perspective”, European Journal of Operational Research, Vol. 276 No. 2, pp. 395-408.

Kovács, G. and Spens, K.M. (2009), "Identifying challenges in humanitarian logistics", International Journal of Physical Distribution and Logistics Management, Vol. 39 No. 6, pp. 506-528.

Kovács, G. and Spens, K.M. (2011), "Trends and developments in humanitarian logistics - a gap analysis", International Journal of Physical Distribution and Logistics Management, Vol. 41 No. 1 , pp. 32-45.

Kovács, G. and Tatham, P. (2009), "Responding to distribution in the supply chain network: from dormant to action", Journal of Business Logistics, Vol. 30 No. 2, pp. 215-229.

Kunz, N. and Gold, S. (2017), "Sustainable humanitarian supply chain management - exploring new theory", International Journal of Logistics Research and Applications, Vol. 20 No. 2, pp. 85-104.

Kunz, N. and Reiner, G. (2016), "Drivers of government restrictions on humanitarian supply chains: an exploratory study", Journal of Humanitarian Logistics and Supply Chain Management, Vol. 6, No. 3, pp. 329-351.

L'Hermitte, C., Bowles, M., Tatham, P. and Brooks, B. (2015), “An integrated approach to agility in humanitarian logistics", Journal of Humanitarian Logistics and Supply Chain Management, Vol. 5 No. 2, pp. 209-233.

Leiras, A., de Brito, I. Jr, Queiroz Peres, E., Bertazzo, R.T. and Yoshida Yoshizaki, H.T. (2014), "Literature review of humanitarian logistics research: trends and challenges", Journal of Humanitarian Logistics and Supply Chain Management, Vol. 4 No. 1, pp. 95-130.

Leonardi, P.M., Huysman, M. and Steinfield, C. (2013), "Enterprise social media: definition, history, and prospects for the study of social technologies in organizations", Journal of Computer-Mediated Communication, Vol. 19 No. 1, pp. 1-19.

Lewin, R., Besiou, M., Lamarche, J.B., Cahill, S. and Guerrero-Garcia, S. (2018), "Delivering in a moving world: looking to our supply chains to meet the increasing scale, cost and complexity of humanitarian needs", Journal of Humanitarian Logistics and Supply Chain Management, Vol. 8 No. 4, pp. 518-532.

Maghfiroh, M.F. and Hanaoka, S. (2017), "Last mile distribution in humanitarian logistics under stochastic and dynamic consideration”, 2017 IEEE International Conference on Industrial Engineering and Engineering Management (IEEM), Singapore, 2017, pp. 1411-1415.

Maiers, C., Reynolds, M. and Haselkorn, M. (2005), "Challenges to effective information and communication systems in humanitarian relief organizations", IEEE International Professional Communication Conference Proceedings, available at: https://ieeexplore.iee.org/document/ 1494163 (accessed 2 October 2020).
Challenges of $\mathrm{HL}$ in disaster relief operations 
JHLSCM 11,1

Makepeace, D., Tatham, P. and Wu, Y. (2017), "Internal integration in humanitarian supply chain management: perspectives at the logistics-programmes interface", Journal of Humanitarian Logistics and Supply Chain Management, Vol. 7 No. 1, pp. 26-56.

Miles, M.B. and Huberman, A.M. (1984), "Drawing valid meaning from qualitative data: toward a shared craft”, Educational Researcher, Vol. 13 No. 5, pp. 20-30.

Miles, M.B. and Huberman, A.M. (1994), Qualitative Data Analysis, SAGE, London.

Moshtari, M. and Gonçalves, P. (2017), "Factors influencing interorganizational collaboration within a disaster relief context", VOLUNTAS: International Journal of Voluntary and Nonprofit Organizations, Vol. 28 No. 4, pp. 1673-1694.

O'Connor, C. and Joffe, H. (2020), "Intercoder reliability in qualitative research: debates and practical guidelines", International Journal of Qualitative Methods, Vol. 19, doi: 10.1177/ 1609406919899220, (accessed 2 October 2020).

Oh, O., Agrawal, M. and Rao, H.R. (2013), "Community intelligence and social media services: a rumor theoretic analysis of Tweets during social crises”, MIS Quarterly, Vol. 37 No. 2, pp. 407-426.

Palen, L., Vieweg, S., Liu, S.B. and Hughes, A.L. (2009), "Crisis in a networked world: features of computer-mediated communication in the April 16, 2007, Virginia Tech event", Social Science Computer Review, Vol. 27 No. 2, pp. 467-480.

Pender, B., Currie, G., Delbosc, A. and Shiwakoti, N. (2014), "Social media use during unplanned transit network disruptions: a review of literature", Transport Reviews: A Transnational Transdisciplinary Journal, Vol. 34 No. 4, pp. 501-521.

Sandwell, C. (2011), "A qualitative study exploring the challenges of humanitarian organizations", Journal of Humanitarian Logistics and Supply Chain Management, Vol. 1 No. 2, pp. 132-150.

Siggelkow, N. (2007), "Persuasion with case studies", Academy of Management Journal, Vol. 50 No. 1, pp. $20-24$.

Stuart, I., McCutcheon, D., Handfield, R., McLachlin, R. and Samson, D. (2002), "Effective case research in operations management: a process perspective", Journal of Operations Management, Vol. 20 No. 5, pp. 419-433.

Tatham, P.H. and Houghton, L. (2011), "The wicked problem of humanitarian logistics and disaster relief aid", Journal of Humanitarian Logistics and Supply Chain Management, Vol. 1 No. 1, pp. 15-31.

Tatham, P. and Kovács, G. (2010), "The application of 'swift trust' to humanitarian logistics", International Journal of Production Economics, Vol. 126 No. 1, pp. 35-45.

Tatham, P., Spens, K. and Kovács, G. (2017), "The humanitarian common logistics operating picture: a solution to the interagency coordination challenge", Disasters, Vol. 41 No. 1, pp. 77-100.

Thomas, J. and Hardens, A. (2008), "Methods for the thematic synthesis of qualitative research in systematic reviews", BMC Medical Research Methodology, Vol. 8, p. 45.

Thomas, A.S. and Kopczak, L.R. (2005), From Logistics to Supply Chain Management: The Path Forward in the Humanitarian Sector, Fritz Institute, available at: http://www.fritzinstitute.org/ PDFs/WhitePaper/FromLogisticsto.pdf (accessed 2 October 2020).

Thomas, A. and Mizushima, M. (2005), "Logistics training: necessity or luxury?", Forced Migration Review, Vol. 22 No. 22, pp. 60-61.

Thomas, A. (2008), Humanitarian Logistics: Enabling Disaster Response, Fritz Institute, San Francisco, available at: http://www.fritzinstitute.org/pdfs/whitepaper/enablingdisasterresponse.pdf (accessed 2 October 2020).

Van Wassenhove, L.N. and Besiou, M. (2013), "Complex problems with multiple stakeholders: how to bridge the gap between reality and OR/MS?", Journal of Business Economics, Vol. 83 No. 1, pp. 87-97.

Van Wassenhove, L.N. (2006), "Humanitarian aid logistics: supply chain management in high gear", Journal of the Operational Research Society, Vol. 57 No. 5, pp. 475-489. 
Voss, C., Tsikriktsis, N. and Frohlich, M. (2002), "Case research in operations management", International Journal of Operations and Production Management, Vol. 22 No. 2, pp. 195-219.

Wamba, S.F., Edwards, A. and Akter, S. (2017), "Social media adoption and use for improved emergency services operations: the case of the NSW SES", Annals of Operations Research, Vol. 283 Nos 1-2, pp. 225-245.

Willis, J.W. (2007), Foundations of Qualitative Research: Interpretive and Critical Approaches, SAGE, Thousand Oaks, CA.

Yan, L.L. and Pedraza Martinez, A. (2019), "Social media for disaster management: operational value of the social conversation", Production and Operations Management, Vol. 28 No. 10, pp. 2514-2532.

Yin, R.K. (2009), Case Study Research: Design and Methods, SAGE, Thousand Oaks, CA.

\section{Further reading}

Babbar, S., Behara, R.S., Koufteros, X.A. and Huo, B. (2017), "Emergence of Asia and Australasia in operations management research and leadership", International Journal of Production Economics, Vol. 184, pp. 80-94.

Besiou, M., Stapleton, O. and Van Wassenhove, L.N. (2011), "System dynamics for humanitarian operations", Journal of Humanitarian Logistics and Supply Chain Management, Vol. 1 No. 1, pp. 78-103.

Heaslip, G., Kovács, G. and Haavisto, I. (2018), "Cash-based response in relief: the impact for humanitarian logistics", Journal of Humanitarian Logistics and Supply Chain Management, Vol. 8 No. 1, pp. 87-106.

Kunz, N. and Reiner, G. (2012), "A meta-analysis of humanitarian logistics research", Journal of Humanitarian Logistics and Supply Chain Management, Vol. 2 No. 2, pp. 116-147.

Lam, H.K.S., Yeung, A.C.L. and Cheng, T.C.E. (2016), "The impact of firms' social media initiatives on operational efficiency and innovativeness", Journal of Operations Management, Vols 47-48, pp. 28-43.

Roulston, K. (2010), Reflective Interviewing: A Guide to Theory and Practice, SAGE, London.

Stake, R. (1998), "Case studies", in Denzin, N.K. and Lincoln, Y.S. (Eds), Strategies of Qualitative Inquiry, SAGE, London.

Su, Y.S., Wardell, C. and Thorkildsen, Z. (2013), Social Media in the Emergency Management Field, CNA, Technical Report, available at: http://cdrmaguire.com/emkey/Resources/Social/ SocialMedia_EmergencyManagement.pdf (accessed 2 October 2020).

Tatham, P. and Spens, K. (2016), "Cracking the humanitarian logistics coordination challenge: lessons from the urban search and rescue community", Disasters, Vol. 40 No. 2, pp. 246-261. 


\section{JHLSCM Appendix 1}

11,1

Table A1.

Table of

interviewee group

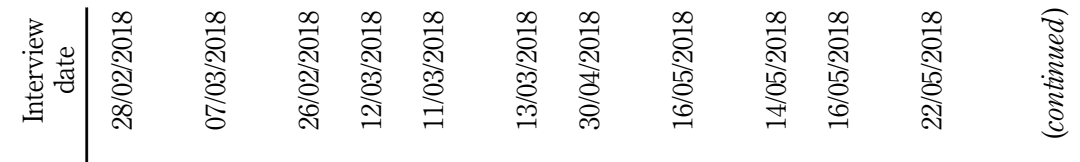

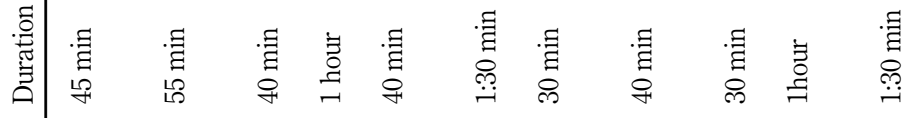

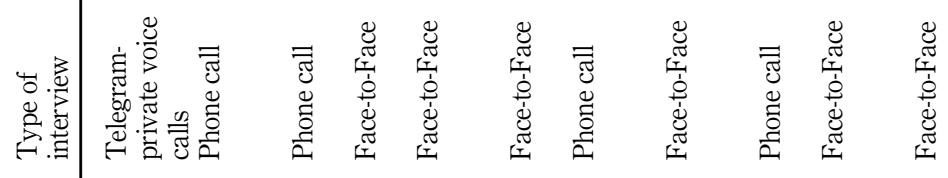

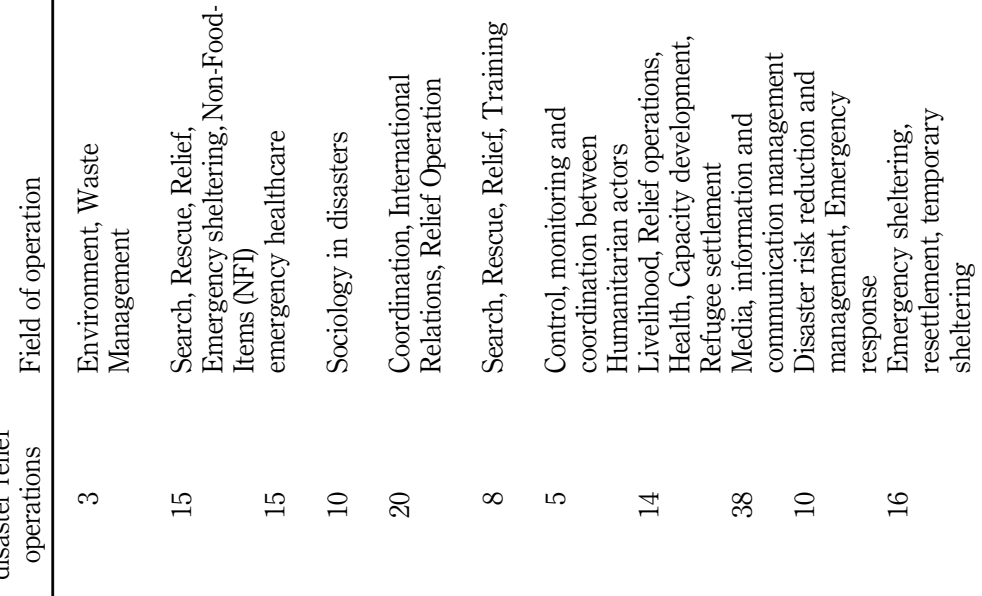

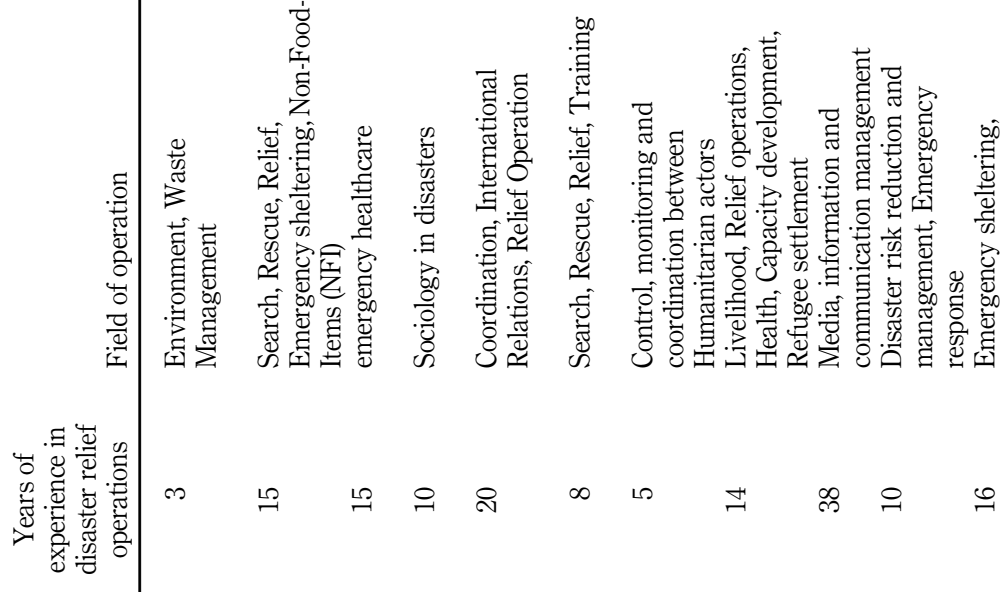

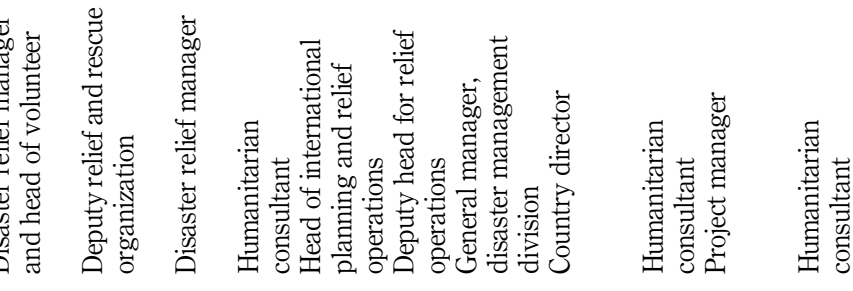

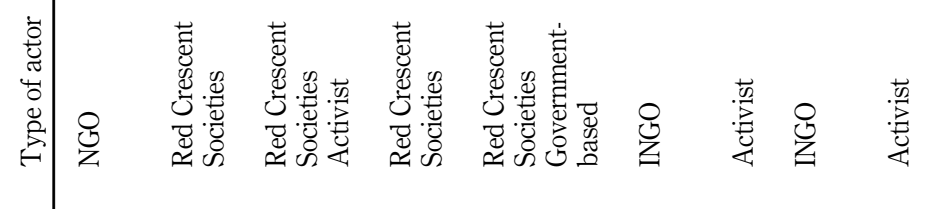
总 


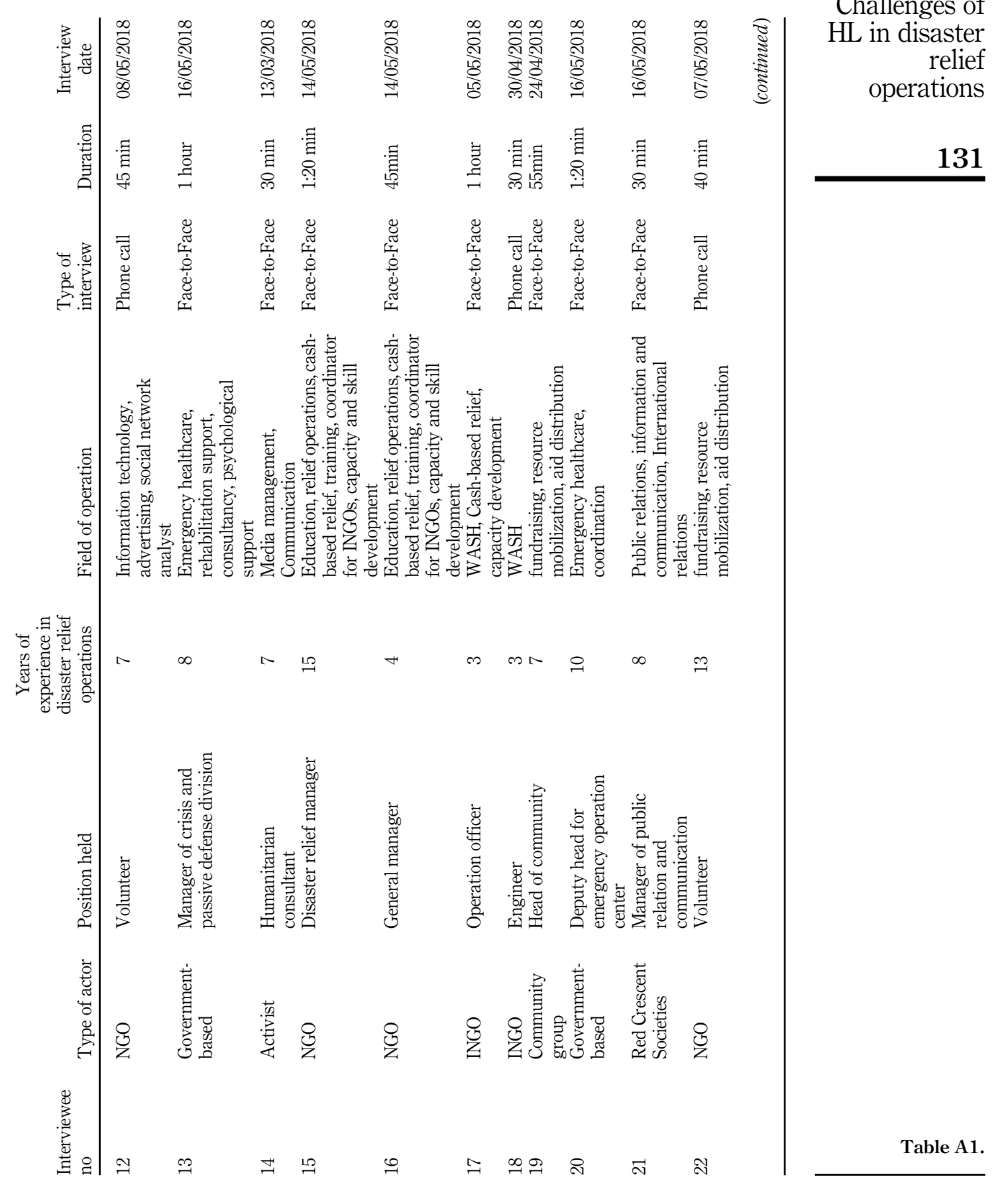




\section{JHLSCM 11,1}

132

Table A1.

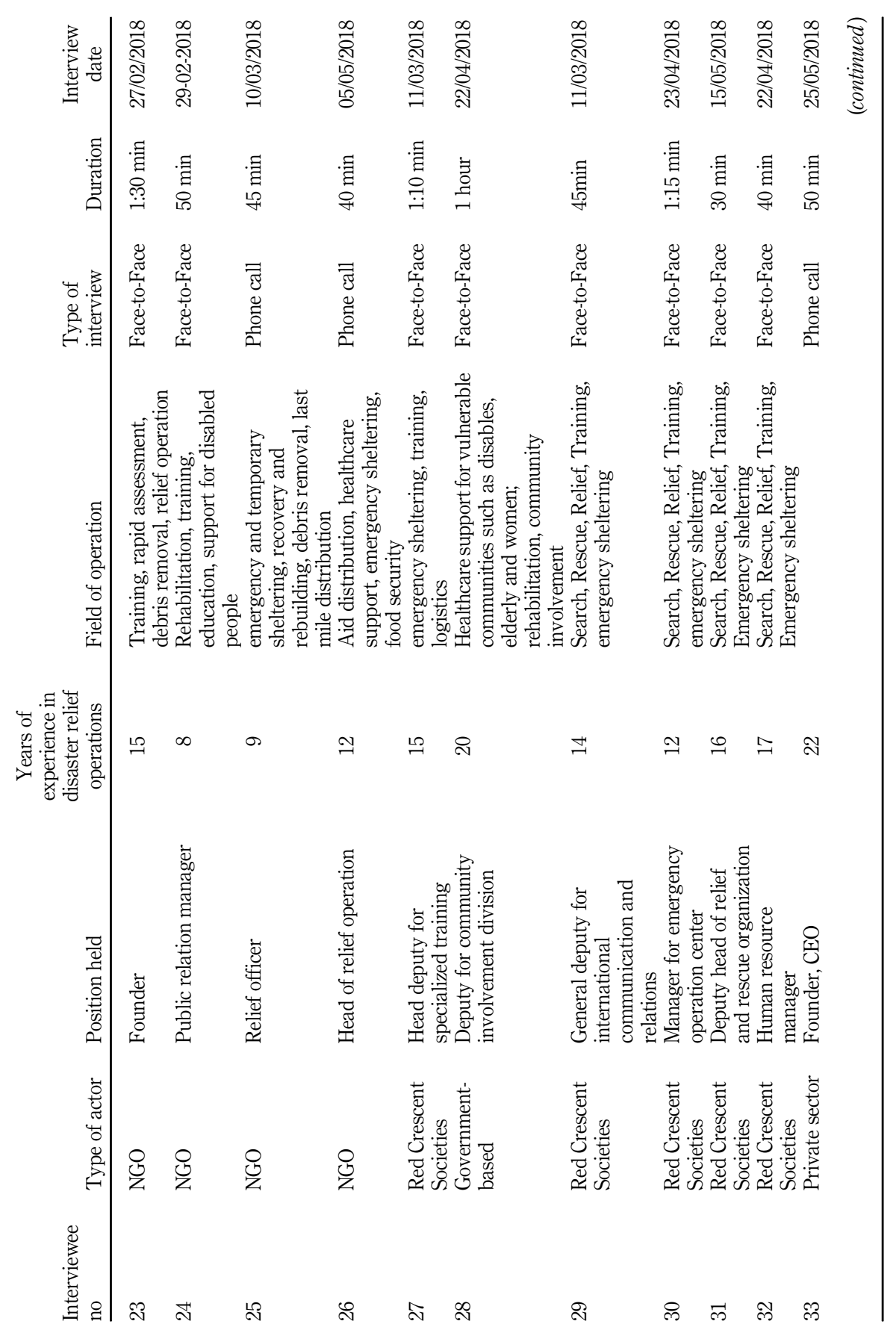




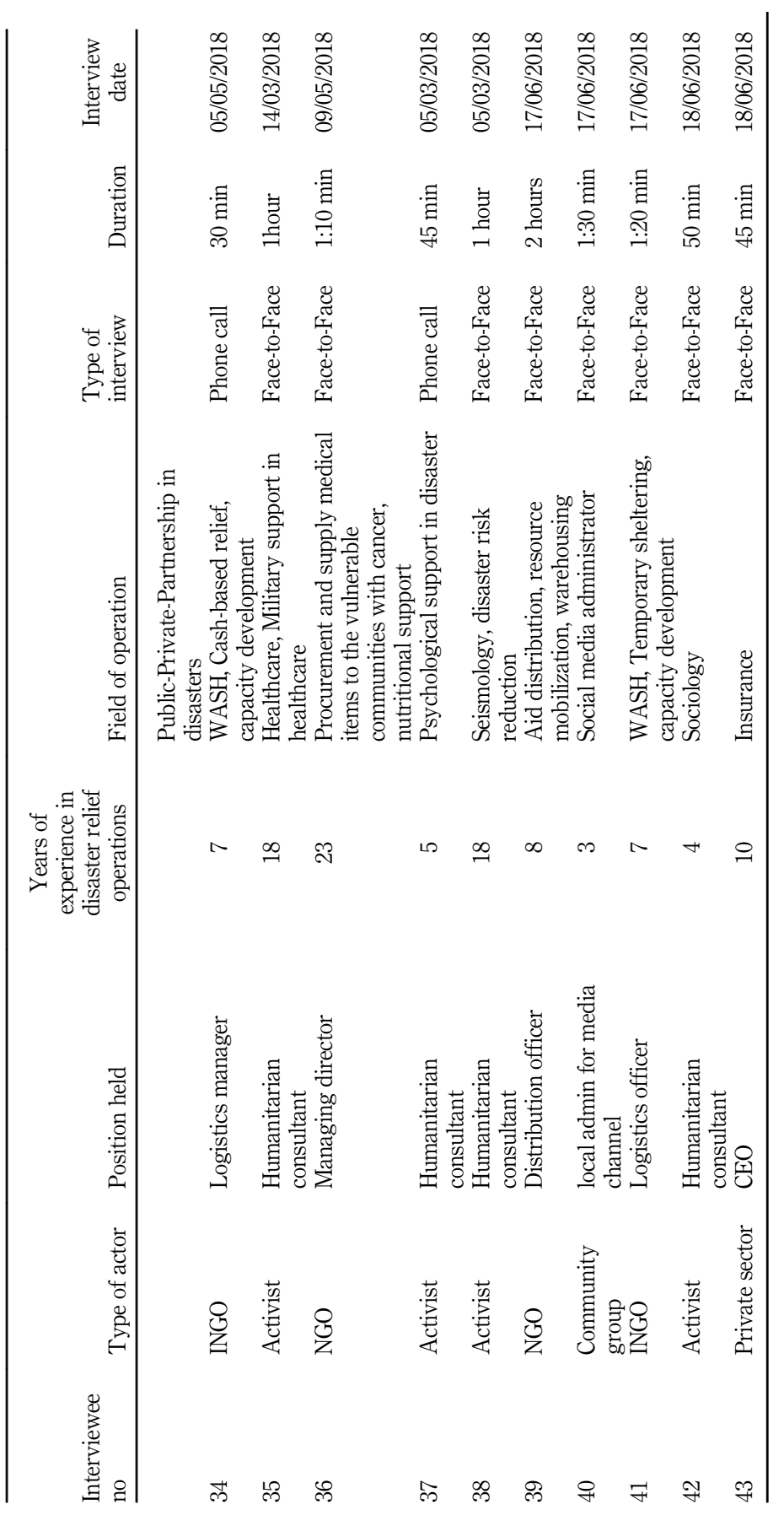

Challenges of $\mathrm{HL}$ in disaster relief operations

133 Table A1. 


\section{JHLSCM 11,1}

\section{Appendix 2 \\ Interview Protocol}

\section{Introduction:}

Explain the research objective. Inform the interviewee that (1) he/she can receive the executive summary of study, (2) all the collected information will be used for academic purposes, (3) any personal or organizational information collected that could identify them will remain strictly confidential and the firm's name will be anonymized in the paper.

\section{Organization General Operations:}

(1) Obtain the title, experience and responsibilities of interviewee, and basic information. Request contact information of other informants within the organization and its partners.

(2) Describe the services or programs provided by the organization, its number of employees and the geographical distribution of its activities.

(3) Describe the organization's role within the humanitarian supply chain network and their relations with other humanitarian actors such as the government, national Red Crescent, NGOs and local communities.

(4) Describe the role of the organization in delivering aid to beneficiaries, and the factors that distinguish it from other actors.

\section{Challenges of HL during disaster relief operations}

(1) Describe the performance outcomes of relief operations in Kermanshah.

(2) Explain whether your organization faced challenges in its operations in the Kermanshah Earthquake (in particular with logistics challenges in terms of needs assessment, procurement, warehousing, transportation and last mile distribution), give examples.

(3) Explain the other challenges and limitations that the focal organization faced during their disaster relief operation in Kermanshah.

\section{Corresponding author}

Amin Maghsoudi can be contacted at: amin.maghsoudi@hanken.fi

For instructions on how to order reprints of this article, please visit our website:

www.emeraldgrouppublishing.com/licensing/reprints.htm

Or contact us for further details: permissions@emeraldinsight.com 